\title{
COMPARATIVE EVALUATION OF THE EPIDURAL DEXMEDETOMIDINE, KETAMINE OR FENTANYL IN COMBINATION WITH BUPIVACAINE IN DOGS
}

\author{
${ }^{1}$ Eman M. Nour, ${ }^{2}$ Mahmoud Mahmoud Othman, \\ ${ }^{3}$ Gamal I.A. Karrouf and ${ }^{4}$ Adel E.I. Zaghloul \\ ${ }^{1}$ Animal Research Facility, Urology and Nephrology Center, \\ Faculty of Medicine, Mansoura University, Mansoura, Egypt \\ ${ }^{2}$ Department of Anesthesia and Surgical ICU, \\ Faculty of Medicine, Mansoura University, Mansoura, Egypt \\ ${ }^{3,4}$ King Fahd Medical Research Center, \\ King Abdulaziz University, P.O. Box: 80216, Jeddah 21589, Saudi Arabia \\ ${ }^{4}$ Department of Surgery, Anesthesiology and Radiology, \\ Faculty of Veterinary Medicine, Mansoura University, Mansoura, Egypt
}

Received 2013-10-24, Revised 2013-11-07; Accepted 2013-11-08

\section{ABSTRACT}

Castration is one of the most common procedure. It is a potential source of mild to moderate pain which is enough to induce inflammatory process, necessitate the incorporation of analgesics. This study was designed to evaluate the effect of epidural bupivacaine alone or in association with fentanyl, ketamine or dexmedetomidine on analgesia for the first $24 \mathrm{~h}$ post surgical castration. Forty male mongrel dogs were randomly allocated into 4 groups received bupivacaine $0.25 \%\left(1.5 \mathrm{mg} \mathrm{kg}^{-1}\right)$ alone or in combination with fentanyl citrate $\left(2 \mu \mathrm{g} \mathrm{kg}^{-1}\right)$ or ketamine hydrochloride $\left(2 \mathrm{mg} \mathrm{kg}^{-1}\right)$ or dexmedetomidine hydrochloride $\left(1.13 \mu \mathrm{g} \mathrm{kg}^{-1}\right)$ into the lumbosacral space. Dogs were scored for sedation using numeric descriptive scale. Analgesia was assessed subjectively through Modified University of Melbourne Pain Scale score and objectively by following up the circulating level of interleukins 6 and 10. The bupivacaine-dexmedetomidine group showed the greatest sedation score, the lowest pain score without neuroendocrine modulation in contrast with bupivacaine or bupivacaine-fentanyl groups. From these result, it is concluded that bupivacaine-dexmedtomidine group provide long term analgesia last for the first $24 \mathrm{~h}$ post operative without additional analgesics.

Keywords: Bupivacaine, Ketamine, Dexmedetomidine, Intereukins, Fentanyl

\section{INTRODUCTION}

Castration of male dogs is frequently performed in veterinary practice. It is assumed to be a mild to moderate painful procedure (Mathews, 2000). It induces inflammatory process followed by neuroendocrine modulation such as increase in serum levels of acute phase proteins and decrease in serum levels of insulin like growth factor I and adiponectin (Tvarijonaviciute et al., 2011).
Post operative pain has deleterious effects that hinder the recovery of the patient. Thus post operative analgesia is of utmost importance (Hansen, 2005) and should start as early as possible. Post operative pain is presumed to peak during the first $24 \mathrm{~h}$ after surgery and this is the time period studied in most clinical trials (Slingsby et al., 2006).

Epidural anesthesia is considered an extremely safe procedure. It can be used efficiently for a wide variety of Corresponding Author: Eman M. Nour, Animal Research Facility, Urology and Nephrology Center, Faculty of Medicine, Mansoura University, Mansoura, Egypt 
surgical procedure to provide intra and post operative analgesia. Epidural anesthesia is preferable than general anesthesia; lower mortality and morbidity, no need for orotracheal intubation, better post operative analgesia and a decrease in surgical stress through blockade of afferent nociceptive pathways and efferent sympathetic impulses.

Based on previous literatures stating that the provided analgesia after epidural lidocaine/tramadol extended up to the $12 \mathrm{~h}$ post castration (Almeida et al., 2010) or as (Slingsby et al., 2006) stressing the need to readministration of a second dose buprenorphine at either four or $6 \mathrm{~h}$ after the first enhanced level of analgesia. Both clarified the short term analgesic effect of different analgesics.

This study is designed to evaluate the usefulness of different epidural regimens to provide prolonged post operative analgesia extended up to the first $24 \mathrm{~h}$ post castration. These compared regimens based on local anesthetic bupivacaine in combination with; Fentanyl, ketamine or dexmedetomidine. Assuming that epidural dexmedetomidine-bupivacaine analgesia will be superior to other combinations analgesia.

\section{MATERIALS AND METHODS}

\subsection{Animals}

Forty male mongrel dogs were kept under controlled environment in the Animal Research Facility Unit, Urology and Nephrology Centre, Mansoura University. Physical examination was used to determine whether the dogs met the inclusion criteria of normal results of neurologic examination, normal biochemical profile normal skin over the epidural injection site and absence of known systemic diseases. None had received previous analgesic treatment. The study was approved by local ethical committee of the faculty of Veterinary Medicine, Mansoura University.

\subsection{Study Design}

The dogs were randomly allocated into 4 groups of 10 each in advance of the study and in order to keep the blindness of the experiment one of colleagues had the key of randomization and was responsible for preparing the different epidural combination served in a similar syringe.

All the assigned groups received bupivacaine $0.25 \%$ $1.5 \mathrm{mg} \mathrm{kg}^{-1}\left(0.6 \mathrm{~mL} \mathrm{~kg}^{-1}\right)$ (Bucaine $0.5 \%$, vial Weimar, German) (Freire et al., 2010) in combination with adjuvants according to randomization; Bupivacine Group (BG): $1 \mathrm{~mL}$ placebo; Ketamine Group (BKG): Ketamine HCL $2 \mathrm{mg} \mathrm{kg}^{-1}$ (Hamilton et al., 2005); Fentanyl Group (BFG): Fentanyl HCL $2 \mu \mathrm{g} \mathrm{kg}^{-1}$ (Almeida et al., 2007);
Dexmedetomidine Group (BDG): Dexmedetomidine HCL $1.13 \mu \mathrm{g} \mathrm{kg}^{-1}$ (Sabbe et al., 1994).

\subsection{Surgical Procedure}

The dog was muzzled to preventbiting, placed on a stainless steel table; clipping and antiseptic preparations were performed on the lumbar region before administration of the epidural agents. A 20 gauge needle was inserted into the lumbosacral space by the technique described by Jones (2001) the correct positioning of the needle was confirmed by the absence of cerebrospinal fluid or blood at the hub and by the hanging drop technique.

Dogs were maintained in sternal recumbency for at least $15 \mathrm{~min}$ to facilitate the uniform distribution of the drugs. Immediately before the beginning of the surgical procedure. A catheter was inserted into the cephalic vein for administration of propofol $7 \mathrm{mg} \mathrm{kg}^{-1} \mathrm{IV}$, followed by continuous infusion of the same agent $0.2 \mathrm{mg} \mathrm{kg}^{-1} \mathrm{~min}$ that was adjusted as necessary to maintain a light plane of anesthesia, Lactated Ringer's solution at a rate of 10 $\mathrm{mL} \mathrm{kg}^{-1} \mathrm{~h}$ was administered during the surgical procedure (Almeida et al., 2007). Then dogs were positioned in dorsal recumbency.

The motor blockade was indicated by motor incoordination of the limb till complete paralysis. Sensory blockade was indicated by absence of groaning, biting attempts, looking at the limb and head shaking by painful stimulus (pressure on interdigital space of hind foot performed with a hemostats protected with rubber) after administration of epidural anesthetics and every $2 \mathrm{~min}$.

All castrations were performed by the same surgeon performed $30 \mathrm{~min}$ after the epidural injection. The incision is made in the skin in front of the scrotum. Each testicle is pushed up through this incision, spermatic cord were clamped then legated with silk (2/0) and transected off. The subcutaneous tissue is sutured using the polygalactin 910 (vicryle Ethicon) absorbable suture materials.

\subsection{Post-Operative Evaluation}

Analgesia and sedation were measured postoperatively at $1,2,3$ and $4 \mathrm{~h}$ post castration while analgesia continued for the first $24 \mathrm{~h}$ post castration.

The degrees of sedation and analgesia were evaluated by the use of Numeric Descriptive Scale (NDS) in which 0 corresponds to no sedation, (1) Mild sedation (Less alert but still active, (2) Moderate sedation (drowsy, recumbent but can walk) and (3) corresponds dogs to intense sedation (Monteiro et al., 2009) and the scale 
proposed by Modified University of Melbourne Pain Scale (UMPS) (Holton et al., 1998) in which 0 corresponds to no pain and 23 to the worst pain possible. Dogs considered being in pain if UMPS equal 8 or more. Dogs were evaluated by the same observer who was unaware of group assignments, which permitted unbiased evaluation of the analgesic effects of the drug.

\subsection{Serum Interleukin-6 (IL-6) and Interleukin- 10 (IL-10)}

Blood samples were collected at $\mathrm{T}_{0}, \mathrm{~T}_{4 \mathrm{~h}}$ and $\mathrm{T}_{24 \mathrm{~h}}$ post operative. Immulite 1000 Analyzer was used for the quantitative measurement of IL-6 and IL-10 in serum. For IL-6 kits the absolute range was nondeductible to $5.9 \mathrm{pg} \mathrm{mL}^{-1}\left(590 \mathrm{ng} \mathrm{dL}^{-1}\right)$ from simens and for IL-10 immulite kits median reference

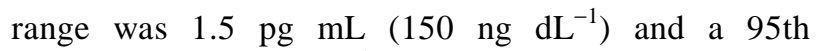
percentile of $9.1 \mathrm{pg} \mathrm{mL}^{-1}$ (910 $\mathrm{ng} \mathrm{dL}$ ) from simens.

\subsection{Statistical Analysis}

The data was done by using SPSS version 17.0 the data were analyzed for normality using KolmogrovSmirnov test. Data were represented as the mean \pm SD for parametric data; latency and duration of motor and sensory blockades, heart rate, non invasive blood pressure, respiratory rate, interleukin-6 and interleukin-10. While non-parametric data were represented as median (IQR) like NDS and Modified UMPS. For parametric data, comparisons were carried out by ANOVA with the least significance post hoc analysis for inter group comparison while for nonparametric data, comparisons were carried out by Kruskal-Wallis H-test followed by Wilcoxon singed rank test for multiple comparison test. Repeated measures ANOVAs were used when data were collected in multiple trials of a single session, followed by the Fisher LSD test. Significance was considered when $\mathrm{P}$ value $<0.05$.

\section{RESULTS}

Forty male mongrel dogs were randomly assigned into four groups: $(\mathrm{N}=10)$ Bupivacaine Group $(\mathrm{BG})$, Bupivacaine/Ketamine Group (BKG), Bupivacaine/Fentanyl Group (BFG) and Bupivacaine/Dexmedetomidine Group (BDG).

Epidural injection of the drugs at the lumbosacral space was easily accomplished in all the dogs and no untoward reactions/complications associated with injection were observed throughout the study.
After administration of propofol all dogs didn't show any gross movements of the forelimbs and head. No differences in the dose of propofol for each group; an induction dose of propofol $\left(7 \mathrm{mg} \mathrm{kg}^{-1}, \mathrm{IV}\right.$, without other premedication), followed by a continuous infusion of the same agent $\left(0.2 \mathrm{mg} \mathrm{kg}^{-1} \mathrm{~min}\right)$ maintaining light plane of anesthesia.

\subsection{Motor and Sensory Blockades}

For latency of motor blockade, it was $(8.60 \pm 2.3 \mathrm{~min}$, $2.4 \pm 0.7 \mathrm{~min}, 7.5 \pm 2.3 \mathrm{~min}$ and $5.1 \pm 1.9 \mathrm{~min}$ ) for $\mathrm{BG}$, $\mathrm{BKG}, \mathrm{BFG}$ and $\mathrm{BDG}$ respectively (with a significantly shorter time for BKG then BDG compared with BG group). For BFG the latency of motor blockade was (7.50 $\pm 2.3 \mathrm{~min}$ ) longer than BKG and BDG but shorter than BG. Duration of motor blockade was $(98 \pm 35.606$ $\min , 177.73 \pm 49.768 \mathrm{~min}, 134.92 \pm 21.748$ and $255 \pm$ $49.554 \mathrm{~min}$ ) for $\mathrm{BG}, \mathrm{BKG}, \mathrm{BFG}$ and $\mathrm{BDG}$ respectively with significant longer duration for $\mathrm{BDG}$ then $\mathrm{BKG}$ compared with BG (Table 1).

As well, latency of sensory blockade, it was (13.10 $\pm 4.1 \mathrm{~min}, 4.27 \pm 1.2 \mathrm{~min}, 10.1 \pm 2.9 \mathrm{~min}$ and $5.1 \pm$ $1.7 \mathrm{~min}$ ) for $\mathrm{BG}, \mathrm{BKG}, \mathrm{BFG}$ and $\mathrm{BDG}$ respectively with significant difference between $\mathrm{BKG}$ and $\mathrm{BDG}$ compared with BG. Duration of the sensory blockade was $(82.50 \pm 34.420 \mathrm{~min}, 171.36 \pm 43.937 \mathrm{~min}$, $126.67 \pm 19.929$ and $242 \pm 46.975 \mathrm{~min}$ ) for $\mathrm{BG}, \mathrm{BKG}$, $\mathrm{BFG}$ and $\mathrm{BDG}$ respectively with significantly longer duration for $\mathrm{BDG}, \mathrm{BKG}$ then $\mathrm{BFG}$ when compared with $\mathrm{BG}$, but for $\mathrm{BKG}$ and $\mathrm{BFG}$; the $\mathrm{BKG}$ had a significantly longer duration when compared with BFG (Table 1).

\subsection{Cytokines}

Supernatant IL-6 concentration from whole blood stimulated with castration significantly differ among groups. BG and BFG showed significant increase $4 \mathrm{~h}$ $\left(303.13 \pm 28.3 \mathrm{ng} \mathrm{dL}^{-1}\right),\left(297.13 \pm 27.7 \mathrm{ng} \mathrm{dL}^{-1}\right)$ and 24 $\mathrm{h}$ post operative $\left(361.13 \pm 21.5 \mathrm{ng} \mathrm{dL}^{-1}\right),(353.13 \pm 19.7$ $\left.\mathrm{ng} \mathrm{dL}^{-1}\right)$ compared with their basal values $\left(258.75 \pm 27.2 \mathrm{ng} \mathrm{dL}^{-1}\right), \quad(255.75 \pm 13.80 \quad \mathrm{ng} \quad \mathrm{dL})$ respectively. BKG showed no change $4 \mathrm{~h}$ post operative $(254.13 \pm 19.4 \mathrm{ng} \mathrm{dL})$ and significant increase $24 \mathrm{~h}$ post operative $\left(331.75 \pm 22.5 \mathrm{ng} \mathrm{dL}^{-1}\right)$ in comparison with the basal value $(260.75 \pm 13.6 \mathrm{ng}$ $\mathrm{dL}^{-1}$ ). While BDG showed no significant changes $4 \mathrm{~h}$ $\left(257.88 \pm 16.1 \mathrm{ng} \mathrm{dL}^{-1}\right)$ or $24 \mathrm{~h}$ post operative (261.88 $\pm 24.12 \mathrm{ng} \mathrm{dL}^{-1}$ ) when compared with control value $\left(262.00 \pm 5.5 \mathrm{ng} \mathrm{dL}^{-1}\right)$. 
The serum concentration of IL- 6 in dogs with epidural injection of B or BFG were signicantly increased $(\mathrm{p}<0.05) 4$ $\mathrm{h}$ post operative compared with BKG and BDG, but $24 \mathrm{~h}$ post operative IL-6 in dogs with epidural injection of B or $\mathrm{BF}$ or $\mathrm{BK}$ were highly signicantly $(\mathrm{p}<0.05)$ increased compared with BDG (Table 2).

Significant difference in the concentration of serum IL10 was observed four and $24 \mathrm{~h}$ post castration. In B and BFG, normal concentration of serum IL-10 were (317.38 $\left.\pm 38 \mathrm{ng} \mathrm{dL}^{-1}\right),\left(320.38 \pm 62.02 \mathrm{ng} \mathrm{dL}^{-1}\right)$ respectively 4 $\mathrm{h}$ post surgical the result of serum IL-10 decreased sigificantly to be $(240.25 \pm 30.041 \mathrm{ng} \mathrm{dL}),(245.7 \pm 13.4 \mathrm{ng}$ $\mathrm{dL}^{-1}$ ) respectively, $24 \mathrm{~h}$ post surgical stimulus serum IL-10 displayed more significant decrease to be $(190.25 \pm 22.23 \mathrm{ng}$ $\left.\mathrm{dL}^{-1}\right),\left(195.4 \pm 10.3 \mathrm{ng} \mathrm{dL}^{-1}\right)$ for both groups respectively.

For BKG, the pre-operative values was $(341.63 \pm 37.627$ ng dL), $4 \mathrm{~h}$ post castration, no significant difference of serum IL-10 was recorded $(330.75 \pm 43.744 \mathrm{ng} \mathrm{dL})$ but $24 \mathrm{~h}$ post castration serum IL-10 was significantly decreased (199.00 $\pm 13.6 \mathrm{ng} \mathrm{dL})$. Other pattern was observed in serum concentration of IL-10 in BDG where no significant difference between pre-operative value $(321.25 \pm 38.6 \mathrm{ng}$ $\mathrm{dL})$ or $4 \mathrm{~h}(320.38 \pm 24.11 \mathrm{ng} \mathrm{dL})$ or $24 \mathrm{~h}$ post castration (331.25 $\pm 16.714 \mathrm{ng} \mathrm{dL})$.
The recorded concentration of serum IL-10 $4 \mathrm{~h}$ post castration in $\mathrm{B}$ and $\mathrm{BF}$ were significantly decreased $(p<0.05)$ compared to the level of IL-10 belong to BK or BD groups. Twenty four hours post castration serum IL10 in BDG was significantly $(\mathrm{p}<0.05)$ increased than $B$, $\mathrm{BF}$ and BK groups (Table 2).

\subsection{Assessment of Sedation (NDS)}

During the postoperative observation period in all groups, the NDS values did vary significantly with time. However, the BDG had the higher sedation values ranged from intense to moderate, which were significantly different in relation to $\mathrm{B}, \mathrm{BF}$ and $\mathrm{BK}$. In dogs received Bupivacaine with or without ketamine or fentanyl, sedation ranged from intense to no sedation, a decrease in all groups was observed with time (Table 3).

\subsection{Assessment of Analgesia (UMPS)}

For analgesia, according to Modified UMPS, an increase in pain scale scores in all groups were observed during the postoperative period except for BDG which showed significantly lower values than in the B, BK and BF groups (Table 4).

Table 1. Latency (Onset of sensory and motor blockades) and duration of motor and sensory blockades in mongrel dogs that received an epidural injection of Bupivacaine (B), Bupivacaine-Ketamine (BK), Bupivacaine-Fentanyl (BF) and Bupivacaine-Dexmedetomidine (BD) groups

\begin{tabular}{lllll}
\hline & B-group $(\mathrm{n}=10)$ & BK-group $(\mathrm{n}=10)$ & BF-group $(\mathrm{n}=10)$ & BD-group $(\mathrm{n}=10)$ \\
\hline Sensory Blockade & & & $10.1 \pm 2.9$ & $5.1 \pm 1.7^{\$}$ \\
Latency (min) & $13.1 \pm 4.1$ & $4.2 \pm 1.2^{\$}$ & $126.6 \pm 19.9^{\$ \#}$ & $242 \pm 46.9^{\$ \# \dagger}$ \\
Duration (min) & $82.5 \pm 34.4$ & $171.3 \pm 43.9^{\$}$ & & $5.1 \pm 1.9^{\$}$ \\
Motor Blockade & & & $7.5 \pm 2.3$ & $255 \pm 49.5^{\$}$ \\
Latency (min) & $8.60 \pm 2.3$ & $2.4 \pm 0.7^{\$}$ & $134.9 \pm 21.7$ & \\
Duration (min) & $98 \pm 35.6$ & $177.7 \pm 49.7^{\$}$ &
\end{tabular}

\$ significant when compared with Bupivacaine group ( $\mathrm{p}<0.05)$, \# significant when compared with Bupivacaine-Ketamine group $(\mathrm{p}<0.05), \dagger$ significant when compared with Bupivacaine-Fentanyl group $(\mathrm{p}<0.05)$. Values are mean \pm SD

Table 2. Interleukin-6 and interleukin-10 levels (ng/dL) in mongrel dogs that received an epidural injection of Bupivacaine (B), Bupivacaine-Ketamine (BK), Bupivacaine-Fentanyl (BF) and Bupivacaine-Dexmedetomidine (BD) groups

\begin{tabular}{llllll}
\hline ILs & Time & B-group $(\mathrm{n}=10)$ & BK-group $(\mathrm{n}=10)$ & BF-group $(\mathrm{n}=10)$ & BD-group $(\mathrm{n}=10)$ \\
\hline IL- 6 & Basal & $258.7 \pm 27.2$ & $260.7 \pm 13.6$ & $255.7 \pm 13.8$ & $262 \pm 5.5$ \\
& 4 h post op. & $303.1 \pm 28.3^{*}$ & $254.1 \pm 19.4^{\$}$ & $297.1 \pm 27.7^{* \#}$ & $257.8 \pm 16.1^{\$}$ \\
& 24 h post op. & $361.1 \pm 21.5^{*}$ & $331.7 \pm 22.5^{*}$ & $353.1 \pm 19.7^{*}$ & $261.8 \pm 24.1^{\$ \# \dagger}$ \\
IL-10 & Basal & $317.3 \pm 66.2$ & $341.6 \pm 37.6$ & $320.3 \pm 62.0$ & $321.2 \pm 38.6$ \\
& 4 h post op. & $240.2 \pm 30.0^{*}$ & $330.7 \pm 43.7^{\$}$ & $245.7 \pm 13.4^{* \#}$ & $320.3 \pm 24.1^{\$ \dagger}$ \\
& 24 h post op. & $190.2 \pm 22.2^{*}$ & $199.0 \pm 13.6^{*}$ & $195.4 \pm 10.3^{*}$ & $331.2 \pm 16.7^{\$ \#+}$ \\
\hline
\end{tabular}

*significant when compared with basal value ( $\mathrm{p}<0.05)$; \$ significant when compared with Bupivacaine group ( $<<0.05)$, \# significant when compared with Bupivacaine-Ketamine group $(\mathrm{p}<0.05)$, $\dagger$ significant when compared with Bupivacaine-Fentanyl group $(\mathrm{p}<0.05)$. Values are mean \pm SD 
Table 3. Numeric Descriptive Scale (NDS) sedation score in mongrel dogs that received an epidural injection of Bupivacaine (B), Bupivacaine-Ketamine (BK), Bupivacaine-Fentanyl (BF) and Bupivacaine-Dexmedetomidine (BD) groups. Used to assess sedation in surgical castrated dogs

\begin{tabular}{lllll}
\hline NDS & B-group $(\mathrm{n}=10)$ & BK-group $(\mathrm{n}=10)$ & BF-group $(\mathrm{n}=10)$ & BD-group $(\mathrm{n}=10)$ \\
\hline T1 h & $3(3.0-3.0)$ & $3.0(3.0-3.0)$ & $3(3.0-3.0)$ & $3(3.0-3.0)$ \\
T2 h & $1.5(1.0-2.0)^{*}$ & $3(3.0-3.00)^{\$}$ & $2(1.75-2.0)^{* \#}$ & $3(3.0-3.0)^{\$ \dagger}$ \\
T3 h & $0(0.0-0.0)^{*}$ & $2(1.0-2.0)^{*}$ & $1(0.75-2.0)^{* \$ \#}$ & $3(3.0-3.0)^{\$ \# \dagger}$ \\
T4 h & $0(0.0-0.0)^{*}$ & $1.5(1.00-2.00)^{*}$ & $0(0.0-0.0)^{* \#}$ & $2(2-3.0)^{* \$ \dagger}$ \\
T5 h & $0(0.0-0.0)^{*}$ & $0(0.0-0.0)^{*}$ & $0(0.0-0.0)^{*}$ & $2(1.0-3.0)^{* \$ H^{*} \dagger}$ \\
\hline
\end{tabular}

* significant when compared with basal value $(\mathrm{p}<0.05)$; \$ significant when compared with Bupivacaine group $(\mathrm{p}<0.05)$, \# significant when compared with Bupivacaine-Ketamine group $(\mathrm{p}<0.05)$, $\dagger$ significant when compared with Bupivacaine-Fentanyl group $(\mathrm{p}<0.05)$. Values are median (IQR)

Table 4. Modified UMPS analgesia score in mongrel dogs that received an epidural injection of Bupivacaine, Bupivacaine-Ketmine, Bupivacaine-Fentanyl and Bupivacaine-Dexmedetomidine groups. Used to assess pain in surgical castrated dogs

\begin{tabular}{|c|c|c|c|c|}
\hline UMPS & B-group $(n=10)$ & BK-group $(n=10)$ & BF-group $(n=10)$ & BD-group $(n=10)$ \\
\hline $\mathrm{T} 1 \mathrm{hr}$ & $3(3.0-3.0)$ & $0.0(0.0-0.0)^{\$}$ & $1(1.0-1.25)^{\$ \#}$ & $0(0.0-0.0)^{\$ \dagger}$ \\
\hline T2hrs & $6(4.7-6.25)^{*}$ & $1(1.0-1.00)^{* \$}$ & $3(3.0-4.0)^{* \$ \#}$ & $0(0.0-0.0)^{\$ \# \dagger \dagger}$ \\
\hline T3hrs & $8(6.25-10.25)^{*}$ & $1(1.0-2.0)^{* \$}$ & $5(3.0-7.0)^{* \$ \#}$ & $0(0.0-0.0)^{\$ \# \dagger}$ \\
\hline T4hrs & $9(6.0-11.0)^{*}$ & $2(1.0-2.25)^{* \$}$ & $7(6.0-8.5)^{* \#}$ & $0(0.0-0.0)^{\$ \#+\dagger}$ \\
\hline T5hrs & $10(8.7-11.0)^{*}$ & $2(1.0-3.0)^{* \$}$ & $10(9.0-11.0)^{* \#}$ & $1(1.0-1.0)^{* \$ \dagger}$ \\
\hline T24hrs & $14(12.7-16.0)^{*}$ & $11(10.0-2.2)^{* \$}$ & $12(11.7-3.0)^{* \$}$ & $3(2.0-3.0) * \$+\phi \dagger$ \\
\hline
\end{tabular}

* significant when compared with basal value $(\mathrm{p}<0.05)$; \$ significant when compared with Bupivacaine group $(\mathrm{p}<0.05)$, \# significant when compared with Bupivacaine-Ketamine group $(\mathrm{p}<0.05)$, $\dagger$ significant when compared with Bupivacaine-Fentanyl group $(\mathrm{p}<0.05)$. Values are median $(\mathrm{IQR})$

\section{DISCUSSION}

Epidural block is one of the most popular, reliable and safe techniques in animals that can provide analgesia for a variety of surgical procedures. The main disadvantage of epidural block is the short duration of action after a single injection (Lloyd-Thomas, 1990). Thus, the use of combinations in epidural anesthesia is considered. In this study, the use of dexmedetomidine, ketamine and fentanyl as adjuvant to bupivacaine was evaluated.

In the present study, all dogs had adequate motor and sensory blockades. The use of bupivacaine alone gave late and short blockade. This was in line with De Segura et al. (2000) reported that latency of bupivacaine alone is to be of 20 to $30 \mathrm{~min}$ post epidural administration. This latency was explained by its moderate onset of action and $95 \%$ plasma protein binding activity (Lamont, 2002).

For the other three compared groups, the latency of blockade was earlier for ketamine-bupivacaine combination followed by dexmedetomidine-bupivacaine whereas it was late for fentanyl-bupivacaine when compared with bupivacaine alone.

Kathirvel et al. (2000) noticed that ketamine added to spinal bupivacaine had local anesthetic-sparing effects in humans. Ketamine possibly diffused from the epidural space into subarachnoid space and then to spinal nerve roots. Hustveit et al. (1995) reported that epidurally administered ketamine produced faster onset explained by ketamine's interaction with mu, delta and kappa opioid receptors.

However, these results were in contrast with, bupivacaine group, (Almeida et al., 2007) who deduced in their study the late latency of both sensory and motor blockades of fentanyl-bupivacaine than bupivacaine $0.5 \%$ alone and also at odds with Gupta et al. (2011) who concluded no difference in latency of motor or sensory blockade between dexmedetomidine or fentanyl added to hyperparic bupivacaine $0.5 \%$. Gandhi et al. (2012) concluded that bupivacaine $0.25 \%$ is faster in inducing motor and sensory blockades than dexmedetomidine-bupivacaine $0.25 \%$ group.

Regarding the duration of blockade, the combination of dexmedetomidine-bupivacaine gave the longest blockade. Followed by ketamine-bupivacaine then Fentanyl-bupivacaine in comparison to bupivacaine.

The prolongation of the motor block of dexmedetomidine-bupivacaine can be explained by the binding of $\alpha_{2}$-adrenoceptor agonists to motor neurons in the dorsal horn (Harada et al., 1995) and the synergism between local anesthetic and $\alpha_{2}$-adrenoceptor agonist (especially for the 2A subtype, which causes it to be a much more effective sedative and analgesic agent (Calzada and de Artinano, 2001). 
For fentanyl-bupivacaine combination, AlGhanem et al. (2009) inferred that epidural administration of morphine-fentanyl shorten the onset of analgesia because fentanyl is a lipophilic $\mu$-receptor agonist opioid, fast onset and a short duration of action, when administerdepidurally rapidly absorbed into epidural fat and the systemic circulatory system, resulting in minimal contact time with spinal opioid receptors.

These results were in line with (Gupta et al., 2011) concluding thatintrathecaldexmedetomidine is associated with prolonged motor and sensory block, hemodynamic stability and reduced demand for rescue analgesics in 24 $\mathrm{h}$ as compared to fentanyl. Almeida et al. (2007) who deduced in their study the late latency of both sensory and motor blockades of fentanyl-bupivacaine than bupivacaine $0.5 \%$ alone.

Associated bradycardia, hypotension and respiratory depression in dexmedetomidine-bupivacaine, fentanylbupivacaine or bupivacaine groups owing to $\alpha_{2}$ adrenoreceptors agonist (Venn et al., 2001), opioid element (Trescot et al., 2008) or rostral spread of the anesthetics with subsequent desensitization of nerves in the sympathetic trunk which have a role in regulation of hemodynamic variables including heart rate and vascular tone, branch off from the thoracolumbar region of the spinal cord (Perez et al., 2013).

NDS, the sedation score used, revealed that dexmedetomidine-bupivacaine combination had the greatest sedation (ranged between intense to moderate allover $4 \mathrm{~h}$ post operative) followed by ketaminebupivacaine and fentanyl-bupivacaine cominatrions (their sedative ranged from intense to no sedation by the $4 \mathrm{~h}$ of observation). bupivacaine had the least sedation, as no sedation was recorded $2 \mathrm{~h}$ postoperative. The sedation was diminished before complete return of pain sensation in the four groups.

Probably, the high values of sedation obtained in combination groups were mostly related to the used anesthetic (propofol). Adding dexmedetomidine, an $\alpha_{2}$ Agonist, promotes sedation by stimulating the locus coeruleus, a part of the brain stem involved in the sleepwake cycle and inhibition of the sympathetic vasomotor center of the brain (Kemp et al., 2008).

However, the sedative effect of dexmedetomidine seemed to decrease over time. Dogs receiving dexmedetomidine appeared quiet and relaxed throughout the study, but easily rousable when interaction was required. This effect has also been described in humans where the sedative effect of dexmedetomidine has been described as arousable or co-operative sedation (Gerlach and Dasta, 2007).
In the present study, dogs in the dexmedetomidinebupivacaine group had significantly the lowest pain scores according to the subjective evaluation using the UMPS compared with dogs in other groups. Dogs in the bupivacaine group were the earliest to express signs of acute pain followed by dogs in fentanyl-bupivacaine group. Whereas Dogs in ketamine-bupivacaine showed high pain scores $24 \mathrm{~h}$ post operative.

These findings were in line with, Singh et al. (2012) estimating that clonidine (an $\alpha_{2}$-agonist) in a dose of 1 $\mu \mathrm{g} \mathrm{kg} \mathrm{kg}^{-1}$, added to $0.25 \%$ bupivacaine for caudal analgesia, for sub-umbilical surgery, significantly prolongs the duration of post-operative analgesia when compared to $0.25 \%$ bupivacaine in normal saline than $0.75 \mathrm{~mL} \mathrm{~kg}^{-1}$ of $0.25 \%$ bupivacaine with ketamine 0.5 $\mathrm{mg} \mathrm{kg}{ }^{-1}$ or $0.75 \mathrm{~mL} \mathrm{~kg}-1$ of $0.25 \%$ bupivacaine with fentanyl $1 \mathrm{mcg} \mathrm{kg}^{-1}$ or $0.75 \mathrm{~mL} \mathrm{~kg}^{-1}$ of $0.25 \%$ bupivacaine alone, without any side effects. Saadawy et al. (2009) as they concluded that caudal dexmedetomidine seems to be a promising adjunct to provide excellent analgesia without side effects over a $24 \mathrm{~h}$ period.

In contrast with the results of the present study, (Cook et al., 1995) comparing the effects of adrenaline, clonidine and ketamine in adjuvant with bupivacaine on the duration of caudal analgesia in children concluded that ketamine produced longer duration of analgesia compared to clonidine (an $\alpha$-agonist) and adrenaline. Almeida et al. (2007) as their dogs administered with the same medications but with different concentration of bupivacaine $(0.5 \%)$ and showed lower pain scores and rescue medication was not needed up to $360 \mathrm{~min}$ after epidural injection, this perhaps due to preanesthetic medication acepromazine administered by $0.1 \mathrm{mg} \mathrm{kg}^{-1} \mathrm{IM}$.

The analgesic effect of the $\alpha_{2}$ agonists is a complex issue, they can induce analgesia by acting at three different sites: In the brain and brain stem, spinal cord and in peripheral tissues. $\alpha_{2}$-adrenergic agonists act on locus coeruleus, representing a supraspinal site of action. In the spinal cord, their analgesic effect is related to activation of the descending medullospinal noradrenergic pathways or to the reduction of spinal sympathetic outflow at presynaptic ganglionic sites (Arian et al., 2004).

Ketamine has analgesic properties that are mediated by a number of mechanisms. NMDA receptor noncompetitive antagonism accounts for most of its analgesic effects through a use-dependent channel blockade (Visser and Schug, 2006). The affinity of ketamine for NMDA receptors is several-fold higher than that for $\mu$ receptors, non-NMDA glutamate receptors, 
nicotinic and muscarinic cholinergic receptors and monoaminergic transporter sites (McCartehy et al., 2004).

In the present study, dogs in the dexmedetomidinebupivacaine group showed no neuroendocrine modulation for the first $24 \mathrm{~h}$ post operative according to the objective evaluation using the interleukins 6 and 10 in comparison with dogs in other groups.

Inteleukin-6 showed no change in its circulating level $4 \mathrm{~h}$ post operativein dexmedetomidine-bupivacaine and ketamine-bupivacaine groups. For fentanyl-bupivacaine and bupivacaine groups IL-6 showed a high level. $24 \mathrm{~h}$ post epidural administration of the different protocols, normal level of IL-6 had been recorded in dexmedetomidine-bupivacaine group in contrast with ketamine-bupivacaine, fentanyl-bupivacaine or bupivacaine groups which showed a rise in circulating IL-6.

Inteleukin-10 showed no change in its circulating level $4 \mathrm{~h}$ post operativein dexmedetomidine-bupivacaine and ketamine-bupivacaine groups. For fentanylbupivacaine and bupivacaine groups IL-6 showed a low level. About $24 \mathrm{~h}$ post epidural administration of the different protocols, normal level of IL-10 had been recorded in dexmedetomidine-bupivacaine group in contrast with ketamine-bupivacaine, fentanylbupivacaine or bupivacaine groups which showed a decrease in circulating IL-10.

The results of ILs- 6 and 10 were similar to those observed by (Kang et al., 2013) in their study thatdexmedetomidine administration during surgery reduced intraoperative and post-operative secretion of cytokines; The pro-inflammatory cytokines tumour necrosis factor $-\alpha$, interleukin $-1 \beta$ and IL- 6 and antiinflammatory cytokines IL-4 and IL-10, as well as postoperative leukocyte count and CRP level. Garcia et al. (2002), in their study showed no preemptive effect of epidural fentanyl plus bupivacaine on postoperative pain and stress response as measured by IL-6 concentrations. Ward et al. (2011) proved that lipopolysaccharide increased the serum concentrations of interleukin (IL)-1 $\alpha$, IL-1 $\beta$, IL-6, IL-10, tumor necrosis factor- $\alpha$ and interferon- $\gamma$ but Ketamine dose dependently attenuated these changes.

Silva et al. (2012) concluded that the epidural injection of $25 \mathrm{mg} \mathrm{S}(+)$-ketamine before incision reduced the pain intensity only $12 \mathrm{~h}$ after surgical incision and did not alter concentration of cytokines (IL-6, TNF- $\alpha$ and IL-10). While Carvalho et al. (2010) demonastrated that bupivacaine wound infusion resulted in a significant decrease of interleukin 10 and increase of substance $P$ in wounds compared with saline infusion, these findings was similar to our as bupivacaine resulted in decrease level of circulating IL-10 4 and $24 \mathrm{~h}$ post operative.

\section{CONCLUSION}

Finally we recommend the use of epidural bupivacaine-dexmedetomidine combination to provide long term analgesia which continued up to the first 24 hrs post- operative without additional analgesics. Also Further study is needed because the current study was limited by; small sample size as well as further objective evaluations such as acute phase proteins, C-reactive proteins and fibrinogen which should be measured for a longer period until the return of biochemical measurements to normal level so that we can monitor the impact of the surgical castration on dogs.

\section{ACKNOWLEDGEMENT}

The research would like to thank Prof. Dr. Ahmed Shokeir the director of Urology and Nephrology Centre.

\section{REFERENCES}

Al-Ghanem, S.M., I.M. Massad, M.M. Al-Mustafa, K.R. Al-Zaben and I.Y. Qudaisat et al., 2009. Effect of adding dexmedetomidine versus fentanyl to intrathecal bupivacaine on spinal block characteristics in gynecological procedures: A double blind controlled study. Am. J. Applied Sci., 6: 882-887. DOI: 10.3844/ajassp.2009.882.887

Almeida, R.M., A. Escobar and S. Maguilnik, 2010. Comparison of analgesia provided by lidocaine, lidocaine-morphine or lidocaine-tramadol delivered epidurally in dogs following orchiectomy. Vet. Anaesth. Analgesia, 37: 542-549. PMID: 21040378

Almeida, T., D.T. Fantoni, S. Mastrocinque, A.C. Tatarunas and V.H. Imagawa, 2007. Epidural anesthesia with bupivacaine, bupivacaine and fentanyl, or bupivacaine and sufentanil during intravenous administration of propofol for ovariohysterectomy in dogs. J. Am. Vet. Med. Assoc., 230: 45-51. PMID: 17199491

Arian, S.R., R.M. Ruehlow, T.D. Uhrich and T.J. Ebert, 2004. The efficacy of dexmedetomidine versus morphine for postoperative analgesia after major inpatient surgery. Anesthesia Analgesia, 98: 153158. PMID: 14693611

Calzada, B.C. and A.A. de Artinano, 2001. Alphaadrenoceptor subtypes. Pharmacol. Res., 44: 195208. PMID: 11529686 
Carvalho, B., D.J. Clark, D.C. Yeomans and M.S. Angst, 2010. Continuous subcutaneous instillation of bupivacaine compared to saline reduces interleukin 10 and increases substance $P$ in surgical wounds after cesarean delivery. Anesthesia Analgesia, 111: 1452-1459. DOI: 10.1213/ANE.0b013e3181f579de

Cook, B., D.J. Grubb, L.A. Aldridge and E. Doyle, 1995. Comparison of the effects of adrenaline, clonidine and ketamine on the duration of caudal analgesia produced by bupivacaine in children. Br. J. Anaesthesia, 75: 698-701. PMID: 8672316

De Segura, I.A.G., I. Vazquez and E. De Miquel, 2000. Antinociceptive and motor-blocking action of epidurally administered IQB-9302 and bupivacaine in the dog. Regional Anesthesia Pain Med., 25: 522528. PMID: 11009240

Freire, C.D., M.L.A. Torres, D.T. Fantoni, R.L. Cavalcanti and J. Noel-Morgan, 2010. Bupivacaine $0.25 \%$ and methylene blue spread with epidural anesthesia in dog. Vet. Anesthesia Analgesia, 37: 63-69. DOI: 10.1111/j.1467-2995.2009.00493.x

Gandhi, R., A. Shah and I. Patel, 2012. Use of dexmedetomidine along with bupivacaine for brachial plexus block. Natl. J. Med. Res., 2: 67-69.

Garcia, J.B.S., A.M. Issy, R. Salomao and R.K. Sakata, 2002. Preemptive analgesia with epidural bupivacaine plus fentanyl in gynaecological surgeryeffects on serum interleukin-6 concentrations. Acute Pain, 4: 23-26. DOI: 10.1016/S13660071(02)00006-2

Gerlach, A.T. and J.D. Dasta, 2007. Dexmedetomidine: An updated review. Ann. Pharmacother., 41: 245254. PMID: 17299013

Gupta, R., R. Verma, J. Bogra, M. Kohli and R. Raman et al., 2011. A comparative study of intrathecaldexmedetomidine and fentanyl as adjuvants to bupivacaine. J. Anaesthesiol. Clin. Pharmacol., 27: 339-343. PMID: 21897504

Hamilton, S.M., S.A. Johnston and R.V. Broadstone, 2005. Evaluation of analgesia provided by the administration of epidural ketamine in dogs with a chemically induced synovitis. Vet. Anesthesia Analgesia, 32: 30-39. PMID: 15663737

Hansen, B.D., 2005. Analgesia and sedation in the critically ill. J. Vet. Emerg. Crit. Care, 15: 285-294. PMID: 15663737

Harada, Y., K. Nishioka, L.M. Kitahata, K. Kishikawa and J.G. Collins, 1995. Visceral antinociceptive effects of spinal clonidine combined with morphine, enkephalin, or U50, 488H. Anesthesiology, 83: 344352. PMID: 7631957
Holton, L.L., E.M. Scott, A.N. Nolan, J. Reid and E. Welsh, 1998. Relationship between physiological factors and clinical pain in dogs scored using a numerical rating scale. J. Small Anim. Pract., 39: 469-474. PMID: 9816569

Hustveit, O., A. Maurset and I. Oye, 1995. Interaction of the chiral forms of ketamine with opioid, phencyclidine, $\sigma$ and muscarinic receptors. Pharmacol. Toxicol., 77: 355-359. PMID: 8835358

Jones, R.S., 2001. Epidural analgesia in the dog and cat. Vet. J., 161: 123-131. PMID: 11243684

Kang, S.H., Y.S. Kim, T.H. Hong, M.S. Chae and M.L. Cho et al., 2013. Effects of dexmedetomidine on inflammatory responses in patients undergoing laparoscopic cholecystectomy. Acta Anaesthesiol. Scandinavica, 57: 480-487. PMID: 23240685

Kathirvel, S., S. Sadhasivam, A. Saxena, T.R. Kannan and P. Ganjoo, 2000. Effects of intrathecal ketamine added to bupivacaine for spinal anaesthesia. Anaesthesia, 55: 899-904. PMID: 10947756

Kemp, K.M., L. Henderlight and M. Neville, 2008. Precedex: Is it the future of cooperative sedation? Nursing, 38: 7-8. PMID: 18362829

Lamont, L.A., 2002. Local Anesthetics. In: Veterinary Anesthesia and Pain Management Secrets, Greene, S.A. (Ed.), Hanley and Belfus Inc., Philadelphia, USA., ISBN-10: 9781560534426, pp: 105-108.

Lloyd-Thomas, A.R., 1990. Pain management in paediatric patients. Br. J. Anaesthesia, 64: 85-104. PMID: 2405898

Mathews, K.A., 2000. Pain assessment and general approach to management. Vet. Clin. North Am. Small Anim. Pract., 30: 729-755. PMID: 10932822

McCartehy, C., A. Sinha and J. Katz, 2004. A qualitative systematic review of the role of N-methyl-Daspartate receptor antagonists in preventive analgesia. Anesthesia Analgesia, 98: 1385-1400. PMID: 15105220

Monteiro, E.R., A. Rodrigues Jr., H.M.Q. Assis, D. Campagnol and J.G. Quitzan, 2009. Comparative study on the sedative effects of morphine, methadone, butorphanol or tramadol, in combination with acepromazine, in dogs. Vet. Anaesthesia Analgesia, 36: 25-33. PMID: 19121156

Perez, T.E., T.L. Grubb, S.A. Greene, S. Meyer and N. Valdez et al., 2013. Effects of intratesticular injection of bupivacaine and epidural administration of morphine in dogs undergoing castration. J. Am. Vet. Med. Assoc., 242: 631-642. PMID: 23402410 
Saadawy, I., A. Boker, M.A. Elshahawy, A. Almazrooa and S. Melibary et al., 2009. Effect of dexmedetomidine on the characteristics of bupivacaine in a caudal block in pediatrics. Acta Anaesthesiol. Scandinavica, 53: 251-256. DOI: 10.1111/j.1399-6576.2008.01818.x

Sabbe, M.B., M.R. Grafe, E. Mjanger, P.J. Tiseo and H.F. Hill et al., 1994. Spinal delivery of sufentanil, alfentanil and morphine in dogs: Physiologic and toxicologic investigations. Anesthesiology, 81: 899920. PMID: 7943841

Silva, E.P.A., R.K. Sakata, J.B.S. Garcia, R. Salomao and A.M. Issy, 2012. Evaluation of preemptive effect of epidural $s(+)$-ketamine for hysterectomy: Plasmatic concentrations of interleukins. Braz. J. Anesthesiol., 62: 3-9. DOI: 10.1016/S00347094(12)70097-1

Singh, J., R.S. Shah, N. Vaidya, P.K. Mahato and B.L. Shrestha et al., 2012. Comparison of ketamine, fentanyl and clonidine as an adjuvant during bupivacaine caudal anaesthesia in paediatric patients. Kathmandu Univ. Med. J., 3: 25-29. PMID: 23434957

Slingsby, L.S., P.M. Taylor and A.E. Waterman-Pearson, 2006. Effects of two doses of buprenorphine four or six hours apart on nociceptive thresholds, pain and sedation in dogs after castration. Vet. Rec., 159: 705-711. PMID: 17114381
Trescot, A.M., S. Datta, M. Lee and H. Hansen, 2008. Opioid pharmacology. Pain Phys., 11: S133-S153. PMID: 18443637

Tvarijonaviciute, A., S. Martinez-Subiela, J.D. Carrillo-Sandez, F. Tecles and J.J. Ceron, 2011. Effects of orchidectomy in selective biochemical analytes in beagle dogs. Reprod. Domestic Anim., 46: 957-963. DOI: $10.1111 / \mathrm{j} .1439$ 0531.2011.01765.x

Venn, R.M., A. Bryant, G.M. Hall and R.M. Grounds, 2001. Effects of dexmedetomidine on adrenocortical function and the cardiovascular, endocrine and inflammatory responses in post-operative patients needing sedation in the intensive care unit. Br. J. Anaesthesia, 86: 650656. PMID: 11575340

Visser, E. and S.A. Schug, 2006. The role of ketamine in pain management. Biomed. Pharmacother., 60: 341348. PMID: 16854557

Ward, J.L., M.T. Harting, C.S. Cox Jr and D.W. Mercer, 2011. Effects of ketamine on endotoxin and traumatic brain injury induced cytokine production in the rat. J. Trauma, 70: 1471-1479. DOI: 10.1097/TA.0b013e31821c38bd 